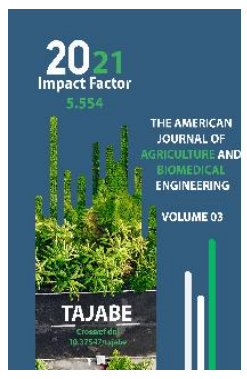

Copyright: Original content from this work may be used under the terms of the creative commons attributes 4.0 licence.

\section{Intensification Of The Drying Process With Vibration Method}

\section{Bahrom Norinbaev}

Candidate Of Technical Sciences, Associate Professor, Department Of Technology Of Storage And Initial Processing Of Agricultural Products, Namangan Engineering-Technology Institute, St. Kasansay 7, Namangan City, Uzbekistan

\section{Nazokathon Jamoliddinova}

Master Student Department Of Technology Of Storage And Initial Processing Of Agricultural Products Namangan Institute Of Engineering Technology, Uzbekistan

\section{Farhodbek Hojimatov}

Master Student Department Of Technology Of Storage And Initial Processing Of Agricultural Products Namangan Institute Of Engineering Technology, Uzbekistan

\title{
ABSTRACT
}

This article describes the use of intensive technologies in the drying of fruits in the project, including the use of vibration boiling to reduce the duration of the drying process and save raw material consumption for 1 ton of dried products by $0.5-2 \%$. Also shows the organoleptic properties of dried plums in vibrating dryers proved to be superior to products obtained from tape-type dryers.

\section{KEYWORDS}

Production technology, basic raw materials, pricing, vibrating, plum.

\section{INTRODUCTION}

Current President of Uzbekistan has identified a "Strategy of Action" on five important priorities for the development of the Republic of Uzbekistan for 2017-2021 to overcome the negative effects of the global economic crisis in our country. Uzbekistan has very good conditions for processing fruits, vegetables and agricultural products. 
During the period of independence, the canning industry of the Republic of Uzbekistan has been reshaping on a private basis. Establishment of new enterprises during the transition to a market economy, expansion of the range of canned goods, filling the domestic market with canned goods, export to the world market, production of high quality canned goods. In order to prevent wasting materials It is advisable to build canneries directly on the farm. The main task of the agricultural processing industry at the present stage is to build modern processing plants and factories where raw materials are grown, increase the range and quantity of canned goods on the world market and create additional jobs. In the context of the global financial and economic crisis, modernization, technical renewal and diversification of production, the widespread introduction of innovative technologies are a reliable way for Uzbekistan to overcome the crisis and reach new heights in the world market.

\section{MATERIAL AND METHODS}

In this regard, the goal of our research is to use these methods in the factory:

1) Convective (the product is washed with heated air).

2) Contact (heat is transferred to the product through the heated surface).

3) Sublimation (using vacuum).

4) Fluidization, in the boiling layer (product particles are lifted and washed with hot air).

5) Increase the concentration and nutritional value of the radiation infrared light zone.

At the beginning of the drying cycle, the drying rate is very high because the moisture in the product is reduced from the substances between the surface of the product and the large cell. Then the drying rate decreases, but remains constant.

With the correct organization of the drying mode, the external and internal diffusion is almost the same and the product is dried evenly. Drying temperature leads to overheating and excessive drying. In addition, the quality of the product changes, the food and the smell disappear.

Many vitamins lose their potency. The main thing is to keep it at a constant temperature during the drying period. An increase in temperature leads to deformation of the product, which slows down the cooking process. The high quality of dried fruits and vegetables is based on air temperature and construction speed. Drying mode depends on the morphological and dimensional properties of the product, the degree of grinding, the method of pre-treatment. Mainly apples, pears, apricots, plums, grapes, potatoes, cabbage, carrots, beets, onions are dried, but other products can also be dried. Raw materials must meet the given standards and be of high quality. Preparation of raw materials consists mainly of sorting, selection by size, washing. The peel and inedible layer of many vegetables and fruits will be removed.

Mechanical cleaning of potatoes and berries is operated by machines and the rest of the process is done manually. At the base of fruits and vegetables are treated with hot water. Washing process of the soft skin is done by machines.

According to P.A. Rebinder, the form of bonding of moisture in the material is physicomechanical, physicochemical and chemical. Usually during the drying process, physicomechanical, physico-chemically bound water evaporates. In the drying of finely dispersed 
materials, first of all, physically and mechanically bound water, ie capillary moisture in micropores, moisture at the joints or moisture of application are released.

Osmotic (physico-mechanical) moisture is located in macropores and is released along with capillary moisture. Polymolecular and monomolecular adsorbed moisture is released after physically and mechanically bound moisture.

The drying process is divided into three stages.

The first stage is a short heating of the material, in which its humidity changes very little. In the second stage - a constant rate of short-term drying of the material, the surface temperature of the material remains unchanged, and the moisture content of the material evaporates as hygroscopic moisture, ie moisture on the surface of the material evaporates from the surface of free water. The third stage is a decrease in the rate of drying, in which the moisture content of the material falls to equilibrium.

The drying process requires a lot of energy. Intensifying this, the invention of low-energy devices remains a real problem. In recent years, the method of vibrating layer in the drying process is gaining popularity. The intensity of drying in this method differs from other methods by the width of the contact surface of the phases and the good mixing of the material, and allows the use of hightemperature drying apparatus.

The conclusion from the above is that in the vibrating layer does not form a vapor barrier layer, which pushes the mass layer of the product from the heater. The thinning formed in the vibrating layer ensures that the steam escapes to the surface layers. The intensity of the vibration effect, ie its frequency, amplitude and oscillations, increases. Increasing the amplitude of the vibrations improves the mixing, resulting in an overall drying rate.

The size of the heat exchange surface of the devices heated from the bottom of the conjunctival heat exchanger is not very high. Therefore, their production efficiency is much lower than convective heat transfer, which performs the function of the heat exchange surface of the entire surface. It is advisable to use the method of conductive heat transfer vibration boiling to dry finely dispersed materials. Due to the heat exchange between the surface of the horizontal vibrating layer and the layer of dispersion material, the heat transfer coefficient is higher than that of a normal vibrating layer.

Raising the vibration parameter to a certain value increases the heat transfer coefficient. In this case, the heating surface forms a gaseous cushion between the dispersed material, which acts as a thermal resistor and adversely affects heat exchange, the optimal heat transfer coefficient in accelerated vibration is radically different from the heat exchange in vertical vibrating layers. 
Study of normative and technical documents for vibration drying of fruits

Study of scientific sources in the implementation of technologies in the field of fruit drying

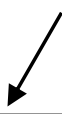

Creating and shaping a working hypothesis of scientific research

Defining the main goals and objectives of research

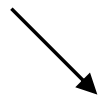

Theoretical and practical substantiation of the technology of intensive drying of fruits

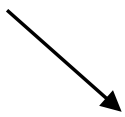

Development of new production technology based on the technology of intensive drying of fruits

Determination of organoleptic properties of the product based on
the technology of intensive drying of fruits

Figure 1. Analysis of the problems of intensification of the drying process of fruits and vegetables 
Schematic diagram of vibratory drying technology of plums

Bringing

Reception

Storage

Washing

Cleaning

Crushing

Sulfidation

Blanching

Drying

Adjust the humidity

Packaging

Storage

\section{Analysis of technological processes of drying plums by vibratory boiling}

The vibration method is one of the most promising areas of application in the pharmaceutical, food and chemical industries. One of the most important processes in this is drying. Heat and mass transfer processes are increasing due to the constant improvement and non-renewal of drying equipment. The most efficient of these devices are dryers, which produce fake boiling and fake liquid layers. The heat treatment of such dryers is as follows: the raw material in the scattering state is located in the type of rapid distribution, and under the influence of heated air, the scattering state becomes liquid. In this case, the layer is constantly softened, mixes well, as a result of which the particles of the dried product are evenly surrounded by hot air.
The above process increases the drying efficiency. In addition, the quality of products dried under the influence of fake boiling layers differs sharply from the usual natural drum dryers and auger and tunnel or belt dryers. Vibrating dryers are structurally simple; the appearance of the material that is being dried is 5-6 times less than the conventional method. Because of the low resistance of the layer, the speed of the heating agent is also low and its contact with the product to be dried is long. Heat consumption in vibrating dryers is 3500$4500 \mathrm{kcal} / \mathrm{kg}$.

\section{RESULTS}

To determine the advantages of the vibrating method of boiling, we conducted experiments on a belt dryer at the plant "Shirinlik" AJ and vibrator dryers and plum dryers installed in this factory. Both experiments were carried out according to the instructions of equipment manufacturers. The results are presented in Table 2.

According to this table, the drying of plums in conventional tape dryers takes 4-5 times longer than in the device of vibratory boiling. $80 \mathrm{~kg}$ of plums of the same weight were dried in 16.5 hours to a moisture content of $24 \%$. Plums of the same weight lasted for 2 hours in the vibrating machine and the moisture content of the product was $24.1 \%$ (Table 3 ). Experiments show that if 4.0 tons of steam are consumed per hour, the SPG-90 dryer consumes 64 tons of steam in 16 hours, and the vibrating dryer consumes only 4.2 tons of water per hour.

Also, the electrical power of these two devices is different. The organoleptic characteristics of dried plums in both devices are given below (Table 1). According to the data, the 
organoleptic characteristics of the product dried by vibration boiling are much better than the tape method.

At the same time, the drying time is reduced by 4 times, and it turned out that the product has a high commodity value. Humidity is $24 \%$. Consumption of raw materials for 1 ton of finished product will be reduced by $18 \mathrm{~kg}$, for the finished product will be $1.9 \%$ more than the amount of sugar in the raw material. This is due to the fact that it is possible to reduce the moisture content of the product to $1 \%$.

It was found that the appearance, color, taste and smell of dried fruits are much better than the products obtained from the tape dryer.

Table 1

Organoleptic characteristics of dried plum

\begin{tabular}{|c|c|c|}
\hline Indicators & Tape drier SPT-90 & Vibrated boiling \\
\hline Appearance & $\begin{array}{c}\text { The fruits are whole, irregularly } \\
\text { shaped or twisted }\end{array}$ & $\begin{array}{c}\text { The fruits are whole, in the } \\
\text { correct form, or light } \\
\text { twisted }\end{array}$ \\
\hline Smell and taste & $\begin{array}{c}\text { Natural, distinctive light sulfur } \\
\text { dioxide taste }\end{array}$ & Natural \\
\hline Color & $\begin{array}{c}\text { Same, distinctive light black to } \\
\text { dark brown } \\
\text { matte }\end{array}$ & The same dark, shiny \\
\hline Humidity $\%$ & 25,1 & 24,1 \\
\hline Amount of raw material for per & 3,7 & 3,52 \\
\hline tonn & $72,1 \%$ & $74 \%$ \\
\hline
\end{tabular}


The American Journal of Agriculture and Boimedical Engineering (ISSN - 2689-1018)

2021: $5 \cdot 554$

Published: March 27, 2021| Pages: 24-31

Doi: https://doi.org/10.37547/tajabe/Volume03Issue03-05

OCLC - 1121105746

Table 3

Technology of drying plums on a tape and vibrating device

\begin{tabular}{|c|c|c|c|}
\hline Process parameters & Large fruits & Small fruits & Vibrating driers \\
\hline $\begin{array}{c}\text { Specific gravity } \\
\mathrm{kg} / \mathrm{m} 2\end{array}$ & 14 & 20 & $60-80 \mathrm{~m} / \mathrm{k}$ \\
\hline $\begin{array}{c}\text { Temperature on tape } \\
\text { First } \\
\text { Second }\end{array}$ & $\begin{array}{c}80 \\
78-80\end{array}$ & $\begin{array}{l}100 \\
95\end{array}$ & $\begin{array}{c}\text { Step } 1 \\
85-900 \mathrm{C} \\
\text { Step 2-750C }\end{array}$ \\
\hline $\begin{array}{l}\text { Third } \\
\text { Fourth }\end{array}$ & $\begin{array}{c}64-70 \\
65\end{array}$ & $\begin{array}{l}90 \\
65\end{array}$ & Step 3-650C \\
\hline $\begin{array}{c}\text { The temperature } \\
\text { velocity } \\
1 \\
2 \\
3 \\
4\end{array}$ & $\begin{array}{l}0,07 \\
0,05 \\
0,03 \\
0,03\end{array}$ & $\begin{array}{l}0.09 \\
0,06 \\
0,04 \\
0,03\end{array}$ & \\
\hline Duration of drying & 16,5 & 6.5 & 2.1 \\
\hline Product output, \% & 24 & 25 & 27,1 \\
\hline
\end{tabular}

\section{CONCLUSION}

1. The use of intensive technologies for drying fruits, including the use of vibration boiling, allows to reduce the duration of the drying process by 4 times.

2. It allows to save $0.5-2 \%$ of raw material consumption for 1 ton of dried product.

3. Plum products dried in vibrating dryers have been shown to have 1.5-2 times better organoleptic properties than products obtained from tape dryers.
4. Due to the complete elimination of sulfur compounds in plum products obtained in the vibrator, its ecological purity is ensured.

5. It was found that the sugar content of dried plums in vibrating dryers is 1.9\% higher than in the tape dryers. This is due to the fact that the optimal moisture content of the fruit is reduced to 1.0 compared to the product in the tape dryer.

1) 6.The moisture in the dried fruit in the vibrator is increased by $3-4$ times during the forging process so that the hardening does 
not form a hard layer on the surface layer of the fruit.

6. Drying of fruits in vibrating dryers is economically feasible and the efficiency of this technology is $16 \%$, with a payback period of 1.92 years.

\section{REFERENCES}

1. Great Russian Encyclopedia.

2. Rogacheva V. I. Handbook of the technologist of fruit and vegetable canning production. M.: Light and food industry, $2001.408 \mathrm{p}$.

3. Zagibalov AF, Zverkova AS, Titova AA, Flaumenbaum BL Technology of fruit and vegetable conservation and product quality control. M.: 2012.352 p.

4. Eliseeva L. G. Commodity research and examination of products of processing of fruits and vegetables: a textbook for universities / L. G. Eliseeva, T. N. Ivanova, O. V. Evdokimova. M.: Dashkov and Co, $2009.376 \mathrm{p}$.

5. GOST 5717-91 Glass jars for canned food. Technical conditions.

6. San. pin 42-123-4117-86 Sanitary rules. Conditions, storage periods.

7. URL: www. bookz.ru. 